\title{
Mapping the Prevalence of Strongyloides stercoralis Infection in Ecuador: A Serosurvey
}

\author{
Angel Gustavo Guevara, ${ }^{1}$ Mariella Anselmi, ${ }^{2}$ Zeno Bisoffi, ${ }^{3,4}$ Rosanna Prandi, ${ }^{2}$ Monica Márquez, ${ }^{2}$ Ronaldo Silva, ${ }^{4}$ Yosselin Vicuña, ${ }^{1}$ \\ Manuel Calvopiña, ${ }^{5}$ William Cevallos, ${ }^{1}$ Jorge Pérez, ${ }^{1}$ Lucy Baldeón, ${ }^{1}$ and Dora Buonfrate ${ }^{4 *}$ \\ ${ }^{1}$ Instituto de Biomedicina, Carrera de Medicina, Universidad Central del Ecuador, Quito, Ecuador; ${ }^{2}$ Centro de Epidemiología Comunitaria y \\ Medicina Tropical (CECOMET), Esmeraldas, Ecuador; ${ }^{3}$ Department of Diagnostics and Public Health, University of Verona, Verona, Italy; ${ }^{4}$ IRCCS \\ Sacro Cuore Don Calabria Hospital, Negrar, Italy; ${ }^{5}$ Escuela de Medicina, Universidad de las Américas (UDLA), Quito, Ecuador
}

\begin{abstract}
Data on the prevalence of strongyloidiasis in Ecuador are patchy. The aim of this study was to document the presence of Strongyloides stercoralis infection in rural communities of different provinces of Ecuador. We tested 1,418 serum samples stored at the biobank of the Central University of Ecuador, Quito, with an ELISA test for Strongyloides. The samples had been collected in eight different provinces of Ecuador. Two hundred ninety-four samples (20.7\%) were positive, and Jipijapa, Manabí Province, was the site with the largest proportion of positive samples (66.7\%). Further surveys aimed at estimating the prevalence of the infection should be carried out in areas where the infection seems highly prevalent, and ad hoc control measures should be adopted.
\end{abstract}

Strongyloidiasis is a soil-transmitted helminthiasis (STH) caused by Strongyloides stercoralis, an intestinal nematode widely distributed in the tropics and subtropics. ${ }^{1}$ According to recent estimates, the number of infected people could exceed 300 million worldwide. ${ }^{2}$ The infection is acquired by skin penetration of the infective larvae living in the soil, and individuals can remain infected for several years (presumably lifelong) if left untreated. The female parasite settles in the intestine, where it lays eggs. The newborn larvae develop into the infective stage when still in the bowel, leading to a cycle of autoinfection and, consequently, to the chronic carrier state. ${ }^{3}$

The burden of morbidity in affected populations is not well defined because studies focusing on this aspect are scant. Nevertheless, a systematic review found that strongyloidiasis can cause urticaria in more than a quarter of the infected individuals in endemic areas. ${ }^{4}$ Furthermore, immunocompromised individuals can experience a sudden increase in the parasitic load because of the acceleration of the autoinfection cycle, potentially causing the so-called disseminated strongyloidiasis, that is, extensive invasion of virtually all organs. This very severe complication, usually occurs when the balance between the host and the parasite, maintained by immune mechanisms in an immunocompetent host, is altered because of several risk factors, among which are malignant hematological diseases (especially lymphoma), immunosuppressive therapy (mainly prednisone), organ transplants, and infection by the human T-cell lymphotropic virus (HTLV-1). ${ }^{3}$

Direct smear of feces and Kato-Katz, techniques that are commonly used in prevalence studies carried out in the field, have an exceedingly low sensitivity for S. stercoralis. ${ }^{5}$ This is the main reason why the prevalence of this parasitic disease has always been underestimated. The Baermann technique and the Koga agar culture have higher sensitivity, although not significantly higher. ${ }^{5}$ Moreover, the complexity of these techniques hampers their use for a rapid assessment of prevalence of strongyloidiasis, although their role is important for individual diagnosis (in particular in immunocompromised patients ${ }^{3}$ ). Conversely, serology is highly sensitive and easy to use in the field, particularly through the collection of blood

*Address correspondence to Dora Buonfrate, IRCCS Sacro Cuore Don Calabria Hospital, Via Sempreboni 5, Negrar 37024, Italy. E-mail: dora.buonfrate@sacrocuore.it samples on filter paper. ${ }^{6}$ Although its specificity is lower than stool-based tests, a diagnostic study showed that specific cutoff levels can define "proven infection."7 Moreover, the higher the prevalence in a population, the better the positive predictive value of the serological tests, making their results reliable in a highly endemic setting. ${ }^{7}$ Serology is also a suitable tool for posttreatment monitoring, as the titers tend to decrease over time till seroreversion. ${ }^{8,9}$ This dynamic of antibody response has also been observed in an observational study carried out in a high-transmission setting. ${ }^{10}$

In Ecuador, there are few data documenting the situation of STH, and particularly of strongyloidiasis. ${ }^{11-15}$ A study carried out in 1997 in schoolchildren aged 5 to 14 years from the community of Borbón, Esmeraldas, ${ }^{15}$ showed that at least $31 \%$ of the children tested were infected with S. stercoralis, which is a worrisome figure considering the possible lifethreatening complications that have been mentioned. Indeed, in the whole country, there are many areas with climatic and environmental conditions that might favor the presence of the parasite.

The aim of this study was to document the presence of $S$. stercoralis infection in rural communities of different provinces of Ecuador.

This was a cross-sectional study conducted on sera previously collected and available in the serum biobank of the laboratory of the Center of Biomedicine of the Central University of Ecuador, Quito, Ecuador. The biological samples were collected in different provinces of the country, in the context of investigations carried out by the Central University of Ecuador, some of them in collaboration with the Center for Community Epidemiology and Tropical Medicine of Esmeraldas. A brief description of the populations and of the study sites is reported in Table 1. Overall, the samples were collected from 2015 to 2018 . The inclusion criterion for samples was all serum samples available in the biobank, belonging to individuals who had given informed consent to the donation of their biological samples for future research purpose. The exclusion criterion was sera belonging to individuals who denied consent. For each patient, information about age, gender, and province of origin was collected in an Excel database, in a strictly anonymous form.

The samples were tested with an immunoenzymatic (ELISA) test for quantitative analysis of Strongyloides ratti lgG antibodies 
TABLE 1

Characteristics of the study sites and population

\begin{tabular}{|c|c|c|}
\hline Population & Site & Main characteristics \\
\hline \multirow[t]{7}{*}{ Entire community } & Jipijapa & $\begin{array}{l}\text { Coastal Ecuador; broadleaf forest; economy based on cultivation of corn, } \\
\text { coffee, and tagua nuts; lack of purified water }\end{array}$ \\
\hline & Chiguilpe and Peripa & $\begin{array}{l}\text { Indigenous community (Tsachila); area of tropical climate, with varied } \\
\text { access to clean water; most workers are farmers/laborers }\end{array}$ \\
\hline & Guapcas & $\begin{array}{l}\text { Andean rural community; the altitude of the site is between } 2,800 \text { and } \\
3,520 \text { m above sea level; agriculture and livestock are main economic } \\
\text { activities }\end{array}$ \\
\hline & 19 de Marzo & $\begin{array}{l}\text { Rural community, in equatorial zone; residents are mostly people coming } \\
\text { from provinces of Chagas-endemic areas (Manabi and Loja) }\end{array}$ \\
\hline & San Antonio de Las Aradas & $\begin{array}{l}\text { Andean rural community; economy based on cultivation of coffee; access } \\
\text { to purified water }\end{array}$ \\
\hline & Awa communities of Esmeraldas Province & Indigenous communities living in rural dispersed areas \\
\hline & Awa communties of Carchi Province & Indigenous communities; rural communities in the subtropical zone \\
\hline \multirow[t]{3}{*}{ Schoolchildren } & Guayllabamba & Andean area, at 2,142 $\mathrm{m}$ above sea level \\
\hline & Uyumbicho & Andean area, at 2,627 $\mathrm{m}$ above sea level \\
\hline & Cañaribamba & Andean area, suburbs of Cuenca \\
\hline
\end{tabular}

in serum (Strongyloides ratti, Bordier Affinity Products, SA, Crissier, Switzerland. The kits were kindly donated by the manufacturer for this study). This test has previously demonstrated a sensitivity of $90.7 \%(95 \% \mathrm{Cl}: 83.8-95.1)$ and specificity ranging from 89 (95\% Cl: 85.1-92.4) to $94.05 \%$ (95\% Cl: 91.2-96.9). ${ }^{7}$ For the study purpose, to be able to compare the results from different runs, the results of the ELISA are reported as a normalized optical density (nOD) value, that is, the ratio between the OD of the sample and that of the weak positive control. A test was positive when $\mathrm{nOD} \geq 1$.

The sample size was based on a convenience and retrospective sampling, the samples having been collected previously and not for the purpose of this study. The protocol received clearance from the Ethics Committee of the Central University of Ecuador on January 16, 2019 (protocol number 038-CE-UCE-2019). Data quality check was performed before

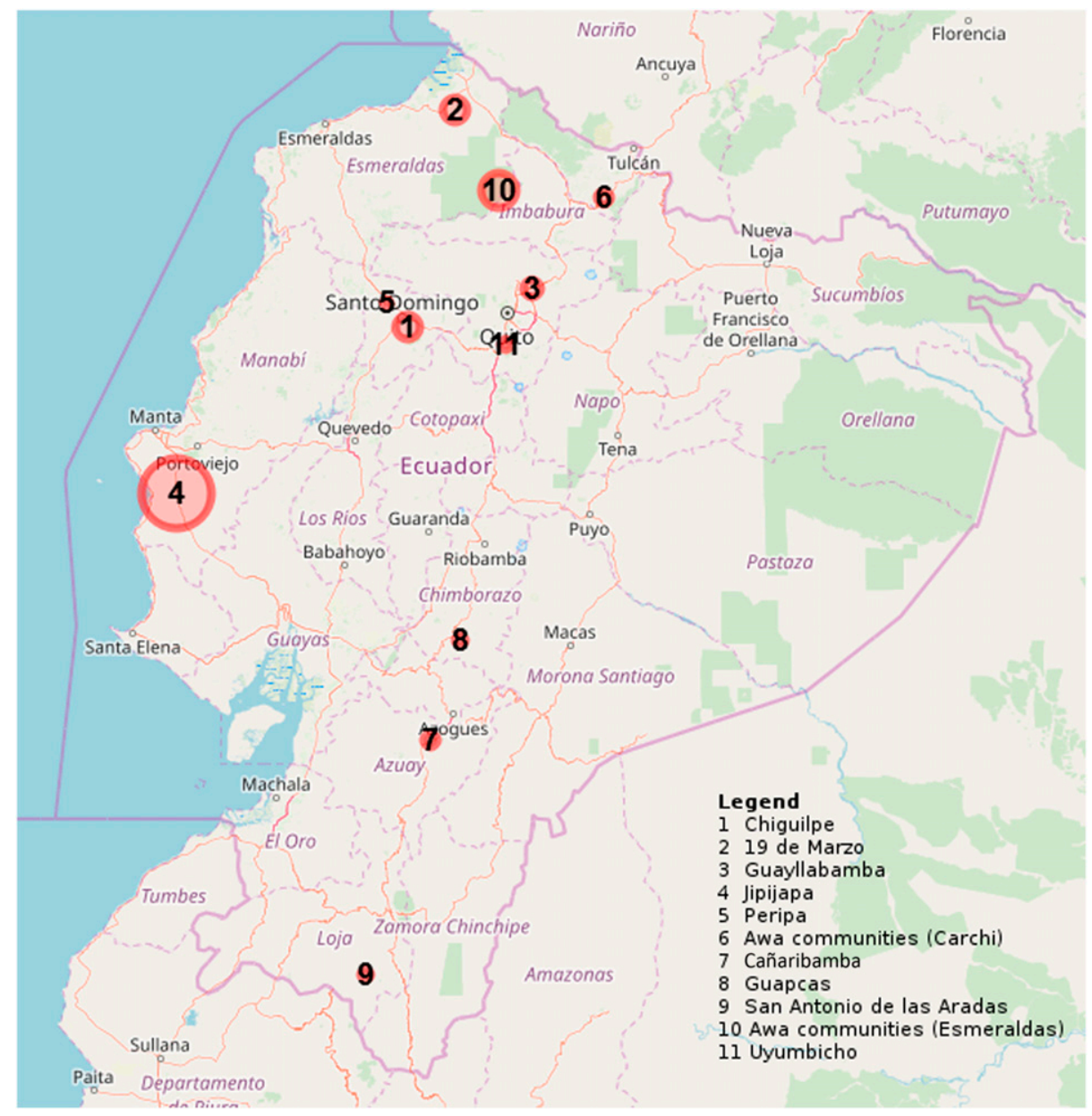

FIGURE 1. Map showing the proportion of positive samples in each study site. This figure appears in color at www.ajtmh.org. 
TABLE 2

Geographical distribution of samples in relation to the general population of the area of origin

\begin{tabular}{|c|c|c|c|c|}
\hline Site & Province & $\begin{array}{l}\text { Population of the } \\
\text { study site } \dagger\end{array}$ & $\begin{array}{l}\text { Screened subjects, } \\
n \text { (\% of population) }\end{array}$ & $\begin{array}{l}\text { Positive for Strongyloides, } \\
n \text { (\% of screened subjects) }\end{array}$ \\
\hline Jipijapa & Manabí & 180 & $24(13.3)$ & $16(66.7)$ \\
\hline Guapcas & Chimborazo & 280 & $126(45.0)$ & $11(8.7)$ \\
\hline Guayllabamba† & Pichincha & 995 & $76(7.6)$ & $13(17.1)$ \\
\hline Uyumbicho† & Pichincha & 1,867 & 92 (4.9) & $8(8.7)$ \\
\hline Cañaribamba† & Azuay & 702 & $97(13.8)$ & $13(13.4)$ \\
\hline Chiguilpe & Santo Domingo de los Tsáchilas & 299 & $26(8.7)$ & $6(23.1)$ \\
\hline Peripa & Santo Domingo de los Tsáchilas & 120 & $18(15.0)$ & $1(5.6)$ \\
\hline $\begin{array}{l}\text { Awa communities of Esmeraldas } \\
\text { Province }\end{array}$ & Esmeraldas & 1,764 & $506(28.7)$ & $170(33.6)$ \\
\hline 19 de Marzo & Esmeraldas & 375 & $75(20.0)$ & $17(22.7)$ \\
\hline Awa communities of Carchi Province & Carchi & 555 & $112(22.9)$ & 16 (14.3) \\
\hline San Antonio de Las Aradas & Loja & 1,263 & $266(21.1)$ & $23(8.6)$ \\
\hline
\end{tabular}
population/), and province official websites (Accessed May 2019). 2) https://www.ubica.ec/info/UYUMBICHO. 3) https://www.infoescuelas.com/ecuador/azuay/unidad-educativa-zoila-aurorapalacios-en-cuenca/. 4) https://www.ubica.ec/info/LUIS-PASTEUR.

† School-based survey. For schools, the "population of the study site" is the total number of schoolchildren attending the school.

analysis. Contingence tables and parameter estimations were performed using Stata/SE14. A map was generated using Google API ${ }^{16}$ and R4 software. ${ }^{17}$

The study population comprised 1,418 serum samples, each one from a single individual. The samples covered eight provinces. Data regarding gender and age were available for 1,403 and 1,406 individuals, respectively. The median age of the donors was 17 years (IQR 7.4-42.1), and females represented $54.3 \%$ of the study population. Specific data on the ethnic group of the individuals tested are not available, although the different groups often reside in definite areas; hence, the information can be partly deduced (but not reported here as we admit it might not be completely accurate). Overall, 294 of 1,418 samples tested $(20.7 \%)$ were ELISA positive. Distribution of the positive results in relation to the geographical area and to the size of the target population is shown in Figure 1 and Table 2. In particular, Jipijapa, Manabí Province, was the site with the largest proportion of positive samples $(66.7 \%)$, followed by the Awa communities in Esmeraldas and in Carchi provinces (33.6\% and $30.1 \%$, respectively). On the other hand, Peripa, Santo Domingo de los Tsáchilas Province, was the area with the smallest proportion (5.6\%) of positive samples. Adults (aged $\geq 18$ years) were more frequently positive to Strongyloides serology (184 of 684, $26.9 \%$ of individuals of that age-group) than children (110 of 734, 14.9\%) $(P<0.0001)$.

Individuals positive to Strongyloides serology were found in all examined districts, confirming that the infection is an issue that should be seriously considered in the country. The larger proportion of infected individuals are adults (aged $\geq 18$ years), probably because of a cumulative exposure over time and of the autoinfection cycle, which does not permit the clearance of the infection without a specific treatment. The lowest proportion was found in a province (Santo Domingo de los Tsáchilas) where mass distribution of ivermectin was delivered for years (up to 2009) in the context of the WHO program for the elimination of onchocercosis; this adds evidence to previous studies demonstrating the usefulness of ivermectin for the community control of strongyloidiasis. ${ }^{12}$ Further surveys should be carried out in areas where the infection seems highly prevalent, and ad hoc control measures for this neglected infection should be adopted.
Received July 30, 2019. Accepted for publication November 7, 2019. Published online December 12, 2019.

Financial support: This work was partly supported by the Italian Ministry of Health "Fondi Ricerca Corrente - Linea 2, progetto 4" to IRCCS Sacro Cuore Don Calabria Hospital.

Authors' addresses: Angel Gustavo Guevara, Jorge Pérez, Lucy Baldeón, Biomedicine, Universidad Central del Ecuador, Quito, Ecuador, E-mails: agguevara@uce.edu.ec,jmperez@uce.edu.ec, and lybaldeon@uce.edu.ec. Mariella Anselmi, Rosanna Prandi, Monica Márquez, Centro de Epidemiologia Comunitaria y Medicina Tropical (CECOMET) Esmeraldas, Ecuador, E-mails: mariella.anselmi@alice.it, rosannaprandi@cecomet.org, and monicamarquez@cecomet.org. Zeno Bisoffi, Ronaldo Silva, and Dora Buonfrate, Department of Infectious and Tropical diseases and Microbiology, IRCCS Sacro Cuore Don Calabria Hospital, Negrar, Italy, E-mails: zeno.bisoffi@ sacrocuore.it, ronaldo.silva@sacrocuore.it, and dora.buonfrate@ sacrocuore.it. Yosselin Vicuña, Colegio de Ciencias de la Salud, Fundación Ecuatoriana para la Investigación en Salud, Universidad San Francisco, Quito, Ecuador, E-mail: yossvi@gmail.com. Manuel Calvopiña and William Cevallos, Centro de Biomedicina, Universidad Central del Ecuador, Quito, Ecuador, E-mails: mcalvopina@hotmail.com and wcevallos@uce.edu.ec.

\section{REFERENCES}

1. Schar F, Trostdorf U, Giardina F, Khieu V, Muth S, Marti H, Vounatsou P, Odermatt P, 2013. Strongyloides stercoralis: global distribution and risk factors. PLoS Negl Trop Dis 7: e2288.

2. Bisoffi Z et al., 2013. Strongyloides stercoralis: a plea for action. PLoS Negl Trop Dis 7: e2214.

3. Nutman TB, 2017. Human infection with Strongyloides stercoralis and other related Strongyloides species. Parasitology 144: 263-273.

4. Tamarozzi F, Martello E, Giorli G, Fittipaldo A, Staffolani S, Montresor A, Bisoffi Z, Buonfrate D, 2019. Morbidity associated with chronic Strongyloides stercoralis infection: a systematic review and meta-analysis. Am J Trop Med Hyg 100: 1305-1311.

5. Requena-Mendez A, Chiodini P, Bisoffi Z, Buonfrate D, Gotuzzo E, Munoz J, 2013. The laboratory diagnosis and follow up of strongyloidiasis: a systematic review. PLoS Negl Trop Dis 7: e2002.

6. Formenti $F$ et al., 2016. Comparison of $S$. stercoralis serology performed on dried blood spots and on conventional serum samples. Front Microbiol 7: 1778.

7. Bisoffi $Z$ et al., 2014. Diagnostic accuracy of five serologic tests for Strongyloides stercoralis infection. PLoS Negl Trop Dis 8: e2640.

8. Buonfrate D et al., 2015. Accuracy of five serologic tests for the follow up of Strongyloides stercoralis infection. PLoS Negl Trop Dis 9: e0003491. 
9. Biggs BA, Caruana S, Mihrshahi S, Jolley D, Leydon J, Chea L, Nuon S, 2009. Management of chronic strongyloidiasis in immigrants and refugees: is serologic testing useful? Am J Trop Med Hyg 80: 788-791.

10. Echazu A et al., 2017. Albendazole and ivermectin for the control of soil-transmitted helminths in an area with high prevalence of Strongyloides stercoralis and hookworm in northwestern Argentina: a community-based pragmatic study. PLoS Negl Trop Dis 11: e0006003.

11. Alcantara-Zafra MC, Martinez-Jimenez T, 2010. Abdominal pain and diarrhea in patients from Ecuador. Rev Esp Enferm Dig 102: 566-567.

12. Anselmi $M$ et al., 2015. Mass administration of ivermectin for the elimination of onchocerciasis significantly reduced and maintained low the prevalence of Strongyloides stercoralis in Esmeraldas, Ecuador. PLoS Negl Trop Dis 9: e0004150.
13. Cooper PJ, Guevara A, Guderian RH, 1993. Intestinal helminthiases in Ecuador: the relationship between prevalence, genetic, and socioeconomic factors. Rev Soc Bras Med Trop 26: 175-180.

14. Jacobsen KH, Ribeiro PS, Quist BK, Rydbeck BV, 2007. Prevalence of intestinal parasites in young Quichua children in the highlands of rural Ecuador. J Health Popul Nutr 25: 399-405.

15. Moreira J, Anselmi M, Van den Ende J, Gobbo M, Endara J, Degani M, Bisoffi Z, 2006. Strongiloidiasi, nei bambini delle scuole elementare di Borbon, Equador: valutazione della prevalenza e della validità dei metodi diagnostici applicando la 'latent class analysis'. Giornale Italiano di Medicina Tropicale 11: 51-55.

16. Google. Google API. Available at: https://console.cloud.google. com/apis/library?pli=1. Accessed November 25, 2019.

17. Graul C, 2016. LeafletR: Interactive Web-Maps Based on the Leaflet JavaScript Library. Available at: https://rdrr.io/cran/leafletR/. Accessed November 25, 2019. 